\section{TRENDS IN WORLD NUCLEAR FORCES, 2017}

\author{
SHANNON N. KILE AND HANS M. KRISTENSEN
}

\section{OVERVIEW}

SIPRI's annual nuclear forces data shows that while the overall number of nuclear weapons in the world continues to decline, all of the nuclear weapon-possessing states are maintaining and modernizing their nuclear arsenals. At the start of 2017 nine states-the United States, Russia, the United Kingdom, France, China, India, Pakistan, Israel and the Democratic People's Republic of Korea (DPRK, North Korea)-possessed approximately 4150 operationally deployed nuclear weapons (see table 1). If all nuclear weapons are counted, these states together possessed a total of approximately 14935 nuclear weapons (see figure 1), compared with approximately 15395 in early 2016.

Global nuclear weapon inventories have been declining since they peaked at nearly 70000 nuclear warheads in the mid 1980s. The decline has been due primarily to cuts made in the Russian and US nuclear forces as a result of three arms limitation treaties since 1991 as well as unilateral force reductions. However, the pace of their reductions is slowing compared with a decade ago, and neither Russia nor the USA-which together account for nearly 93 per cent of nuclear weapons in the world-has indicated that it will make

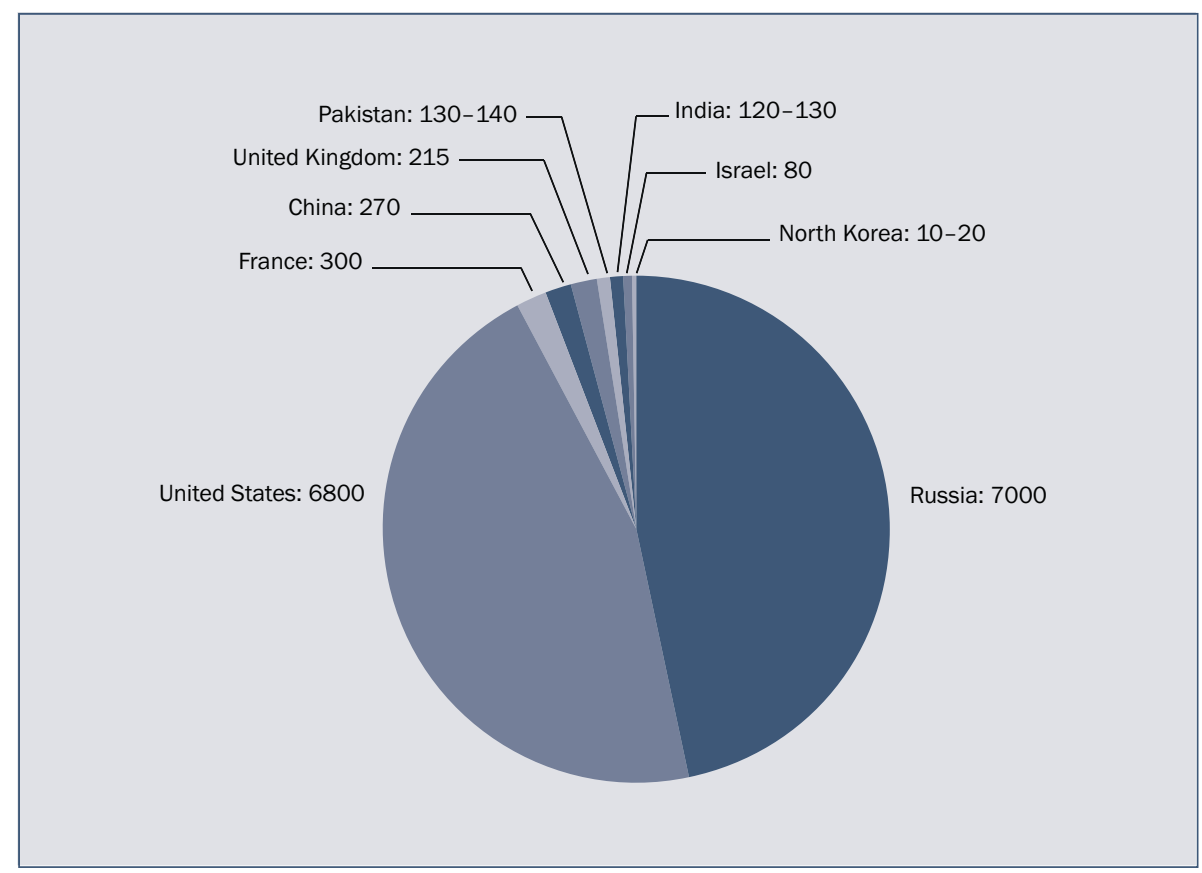

Figure 1. World nuclear forces, share of world total by country, 2017

Note: All figures are approximate.

\section{KEY FACTS}

- At the start of 2017 nine states-the United States, Russia, the United Kingdom, France, China, India, Pakistan, Israel and the Democratic People's Republic of Korea (DPRK, North Korea)possessed approximately 14935 nuclear weapons.

- None of the nuclear weaponpossessing states are prepared to give up their nuclear arsenals for the foreseeable future. All of these states are either developing or deploying new weapon systems or have announced their intention to do so.

- India and Pakistan are expanding their military fissile material production capabilities on a scale that may lead to significant increases in the size of their nuclear weapon inventories over the next decade.

- The USA plans to spend $\$ 400$ billion over the period 2017-26 to maintain and modernize its nuclear forces, buy replacement systems and upgrade its nuclear weapon production infrastructure.

- By some estimates, the USA will spend up to $\$ 1$ trillion by the mid 2040s on its nuclear modernization programmes.

- North Korea appears to have made technical progress in its military nuclear and ballistic missile programmes and may have built up to 20 nuclear warheads. However, there is no open-source evidence that North Korea has produced nuclear warheads that can be carried on ballistic missiles. 
Table 1. World nuclear forces, January 2017

All figures are approximate. The estimates presented here are based on public information and contain some uncertainties, as reflected in the table notes.

\begin{tabular}{|c|c|c|c|c|c|}
\hline Country & $\begin{array}{l}\text { Year of first } \\
\text { nuclear test }\end{array}$ & $\begin{array}{l}\text { Deployed } \\
\text { warheads }^{a}\end{array}$ & $\begin{array}{l}\text { Stored } \\
\text { warheads }^{b}\end{array}$ & $\begin{array}{l}\text { Other } \\
\text { warheads }\end{array}$ & $\begin{array}{l}\text { Total } \\
\text { inventory }\end{array}$ \\
\hline USA & 1945 & $1800^{c}$ & $2200^{d}$ & $2800^{e}$ & 6800 \\
\hline Russia & 1949 & $1950^{f}$ & $2350^{g}$ & $2700^{e}$ & 7000 \\
\hline UK & 1952 & 120 & 95 & - & 215 \\
\hline France & 1960 & 280 & 10 & 10 & 300 \\
\hline China & 1964 & - & 270 & - & 270 \\
\hline India & 1974 & - & $120-130$ & .. & $120-130$ \\
\hline Pakistan & 1998 & - & $130-140$ & .. & $130-140$ \\
\hline Israel & .. & - & 80 & .. & 80 \\
\hline North Korea & 2006 & - & .. & $(10-20)$ & $(10-20)^{h}$ \\
\hline Total $^{i}$ & & 4150 & 5275 & 5510 & 14935 \\
\hline
\end{tabular}

.. = not applicable or not available; $-=$ zero; ()$=$ uncertain figure.

${ }^{a}$ These are warheads placed on missiles or located on bases with operational forces.

${ }^{b}$ These are warheads in central storage that would require some preparation (e.g. transport and loading on to launchers) before they could become fully operationally available.

${ }^{c}$ This figure includes approximately 1650 strategic warheads (about 1350 on ballistic missiles and nearly 300 on bomber bases), as well as c. 150 non-strategic (tactical) nuclear bombs deployed in Europe for delivery by US and other North Atlantic Treaty Organization combat aircraft.

${ }^{d}$ This figure includes $c .150$ non-strategic nuclear bombs stored in the USA.

${ }^{e}$ This figure is for retired warheads awaiting dismantlement.

$f_{\text {This number includes approximately } 1750 \text { strategic warheads on ballistic missiles }}$ and about 200 deployed on heavy bomber bases.

${ }^{g}$ This figure includes $c .500$ warheads for strategic bombers and nuclear-powered ballistic missile submarines (SSBNs) in overhaul and c. 1850 non-strategic nuclear weapons for use by short-range naval, air force and air defence forces.

${ }^{h}$ There is no open-source evidence to confirm that North Korea has produced or deployed operational nuclear warheads.

${ }^{i}$ Total figures assume the highest estimate when a range is given. further reductions in its strategic nuclear forces beyond the modest cuts mandated by the 2010 Treaty on Measures for the Further Reduction and Limitation of Strategic Offensive Arms (New START) (see figure 2). Furthermore, both Russia and the USA have extensive and expensive modernization programmes under way for their remaining nuclear delivery systems, warheads and production facilities.

The nuclear arsenals of the other nuclear weapon-possessing states are considerably smaller (see figure 3 ), but all are either developing or deploying new weapon systems or have announced their intention to do so. China has embarked on a long-term modernization programme focused on making qualitative improvements to its nuclear forces rather than on significantly increasing their size. India and Pakistan are both expanding their nuclear weapon stockpiles as well as developing new land-, sea- and air-based missile delivery systems. Israel, which neither officially confirms nor denies that it possesses nuclear weapons, is testing a long-range nuclear-capable ballistic missile. North Korea continues to prioritize its military nuclear and ballistic missile programmes, but there is no open-source evidence that North Korea has weaponized and deployed nuclear warheads with operational forces.

This Fact Sheet presents estimates of the nuclear weapon inventories of the nine nuclear weapon-possessing states and highlights some key aspects of the states' recent nuclear-force developments.

\section{US NUCLEAR FORCES}

As of January 2017 the USA maintained an active stockpile of about 4000 nuclear warheads. This represented a reduction of approximately 500 warheads compared with early 2016 , as a result of a unilateral cut ordered by US President Barack Obama. The active stockpile included approximately 1800 warheads deployed on land- and sea-based ballistic missiles and at bomber bases, consisting of nearly 1650 strategic and 150 non-strategic (tactical) warheads. In addition, about 2200 warheads were held in reserve and 
roughly 2800 retired warheads were awaiting dismantlement, giving a total inventory of approximately 6800 nuclear warheads.

The USA has begun an ambitious modernization of its triad of land-, seaand air-based nuclear forces and the facilities that support them. The programmes include: a new nuclear-capable long-range bomber, known as the B-21, that will replace existing B-52H and B-1B bombers during the 2030s and 2040s; a new stealthy air-launched cruise missile, known as the LRSO (Long-Range Standoff missile), that will have greater range and accuracy than the current system; a next-generation intercontinental ballistic missile (ICBM), known as the Ground Based Strategic Deterrent (GBSD), that is scheduled to begin replacing the Minuteman III ICBM in 2028; and a nextgeneration nuclear-powered ballistic missile submarine (SSBN), known as the Columbia class, that will replace the current Ohio class beginning in 2031. The USA is also modernizing its inventory of B61 nuclear gravity bombs, which is the sole component of the US tactical nuclear arsenal, with the introduction of a new B61-12 guided bomb that will have improved accuracy and expanded strike options.

According to the US Congressional Budget Office, the total cost of modernizing the USA's nuclear forces and related infrastructure will be approximately $\$ 400$ billion over the 10 -year period $2017-26$. Some analysts predict that the USA will spend approximately $\$ 1$ trillion by the mid 2040s on maintaining the current arsenal, buying replacement systems, modernizing nuclear command and control facilities, and building new nuclear weapon production and simulation facilities.

\section{RUSSIAN NUCLEAR FORCES}

As of January 2017 Russia maintained an active stockpile of approximately 4300 nuclear warheads. The stockpile included roughly 2460 strategic warheads, of which nearly 1950 were deployed on ballistic missiles and at bomber bases. Russia also possessed approximately 1850 non-strategic (tactical) nuclear warheads, all of which were in central storage. An additional roughly 2700 warheads were retired or awaiting dismantlement, giving a total inventory of approximately 7000 warheads.

Russia's ICBM force is being gradually modernized as Soviet-era missiles are replaced by new systems, albeit not on a one-for-one basis. The ICBM force carries approximately 60 per cent of Russia's deployed strategic warheads. Russia is seeking to maintain rough strategic parity with the USA by limiting future reductions in the number of missile launchers and maximizing the number of warheads carried on them. The Russian Strategic Rocket Force is prioritizing deployment of multiple independently targetable re-entry vehicles (MIRVs) on its new RS-24 Yars (SS-27 Mod 2) mobile ICBMs. It is also developing a new silo-based 'heavy' ICBM, known as the RS-28 (Sarmat or SS-30), that can carry up to 10 MIRVed warheads and reportedly will be equipped with advanced countermeasures designed to penetrate US missile defence systems.

To replace its ageing fleet of Soviet-era SSBNs by the end of the next decade, Russia is building eight Borei class SSBNs (Project 955/A), three of which had entered service by 2016. According to some reports, four more Borei SSBNs have been ordered. The new submarines will each carry 
16 Bulava (SS-N-32) submarine-launched ballistic missiles (SLBMs) armed with up to 6 warheads.

Russia is modernizing its Tu-160 and some of its ageing Tu-95MS bombers to maintain a bomber force of 50-60 aircraft. Because of delays in developing the next-generation bomber programme, Russia has resumed production of the Tu-160, with at least 50 aircraft to be procured beginning in 2023.

Russia does not provide information about the number and locations of its non-strategic nuclear weapons. It is estimated that there are approximately 1850 warheads assigned for potential use on sea-launched cruise missiles (SLCMs), ground-based short-range ballistic missiles, and combat aircraft. There is considerable uncertainty about the extent to which Russia still relies on nuclear warheads for air-, coastal- and missile-defence forces.

\section{BRITISH NUCLEAR FORCES}

As of January 2017 the UK's nuclear stockpile consisted of approximately 215 warheads. Of this total, 120 warheads were operationally available. The overall size of the British nuclear stockpile, including non-deployed warheads, will be reduced to no more than 180 warheads by the mid 2020s.

The British nuclear deterrent consists exclusively of a sea-based component: four Vanguard class Trident SSBNs that can be armed with up to 16 Trident II D5 SLBMs. The UK leases the missiles from the US Navy.

In its 2015 Strategic Defence and Security Review, the British Government announced that it intended to replace the four Vanguard class SSBNs with a new class of four submarines. As part of this 'like-for-like' replacement programme, the Royal Navy will maintain for the indefinite future the current posture, known as continuous at-sea deterrence (CASD), whereby one of the four SSBNs is on patrol at all times

In July 2016 the British Parliament approved by a wide margin a motion supporting the Trident successor programme. The motion did not give final approval for the new programme. In order to control costs, the government had previously announced that approval for the investment, estimated to total $£ 31$ billion ( $\$ 45.2$ billion), would be given in stages rather than as a single 'main gate' decision.

The new submarine, known as the Dreadnought, will be similar to the Vanguard class and will initially carry Trident II D5 SLBMs. Its entry into service has been delayed until the early 2030s as part of an extended development and acquisition programme. Replacement of the current warhead for the Trident missiles has been similarly postponed, until at least the late 2030s.

\section{FRENCH NUCLEAR FORCES}

France's nuclear arsenal comprises approximately 300 warheads. The size of the inventory has remained stable in recent years.

The main component of France's strategic nuclear deterrence force consists of four Triomphant class SSBNs, each of which carries 16 SLBMs. France is modifying the Triomphant class submarines to carry the M51 SLBM, which has improved range and accuracy compared with the ageing M45 missile. It is also beginning preliminary design work on a next-generation SSBN, 
with the goal of having a successor submarine to the Triomphant class in service by 2035 .

The airborne component of the French nuclear forces consists of the land-based Mirage 2000N and Rafale F3 combat aircraft; and the Rafale MF3 deployed on the aircraft carrier Charles de Gaulle. The aircraft are equipped with the ASMP-A medium-range air-to-surface cruise missile, which entered service in 2009. A midlife refurbishment programme for the ASMP-A is scheduled to begin in 2022 that will allow the missile to continue in service until the mid 2030s. The French Ministry of Defence has initiated studies for a successor missile, with a focus on enhanced stealth and

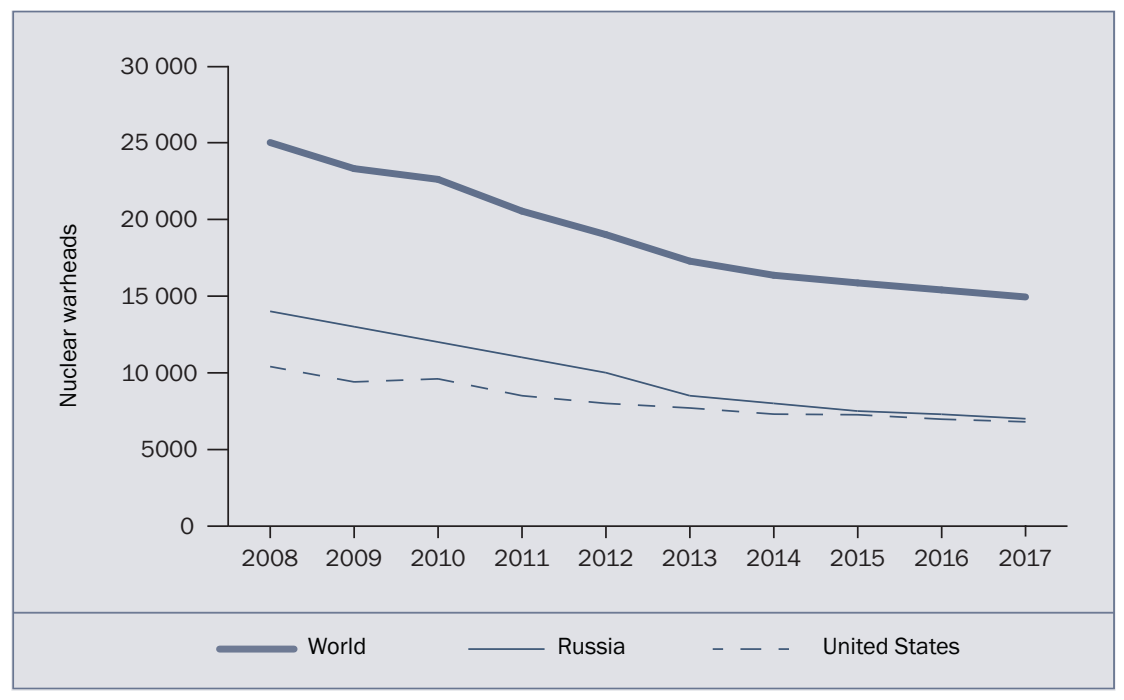

Figure 2. Total warhead holdings of all nuclear-weapon possessing states (the United States, Russia, the United Kingdom, France, China, India, Pakistan, Israel and North Korea) compared with Russian and US holdings, 2008-17 hypersonic technologies.

\section{CHINESE NUCLEAR FORCES}

China continues to modernize its nuclear arsenal as part of a long-term programme to develop more survivable and robust forces consistent with its nuclear strategy of assured retaliation. It maintains an estimated total stockpile of about 270 nuclear warheads, a number that is slowly increasing. Of China's planned triad of land-, sea- and air-based nuclear forces, only the land-and sea-based ballistic missiles are currently considered operational.

China's nuclear-capable land-based ballistic missile arsenal is undergoing gradual modernization as ageing silo-based, liquid-fuelled missiles are replaced by more survivable mobile solid-fuelled models. China is developing the DF-41, a new road-mobile ICBM with a range that will reportedly allow it to strike targets throughout continental USA, but it is unclear when the missile will enter into service. China is concurrently investing in improved communication capabilities for its nuclear forces to ensure the integrity of command and control arrangements for a larger, more dispersed mobile missile force.

After many years of development work, China appears to have modified some of its ICBMs to be able to deliver nuclear warheads in MIRVs. According to US Department of Defense assessments, China has deployed MIRVs on a small number of silo-based ICBMs (DF-5B). China has prioritized the deployment of MIRVs in order to improve its warhead penetration capabilities in response to advances in US and, to a lesser extent, Indian missile defences.

China is developing a sea-based nuclear deterrent consisting of a fleet of Type 094 SSBNs. The Type 094 SSBN will eventually be armed with up to $12 \mathrm{JL}-2$ SLBMs, but the missile programme has encountered delays due to technical difficulties and the missile has not yet entered operational service. 


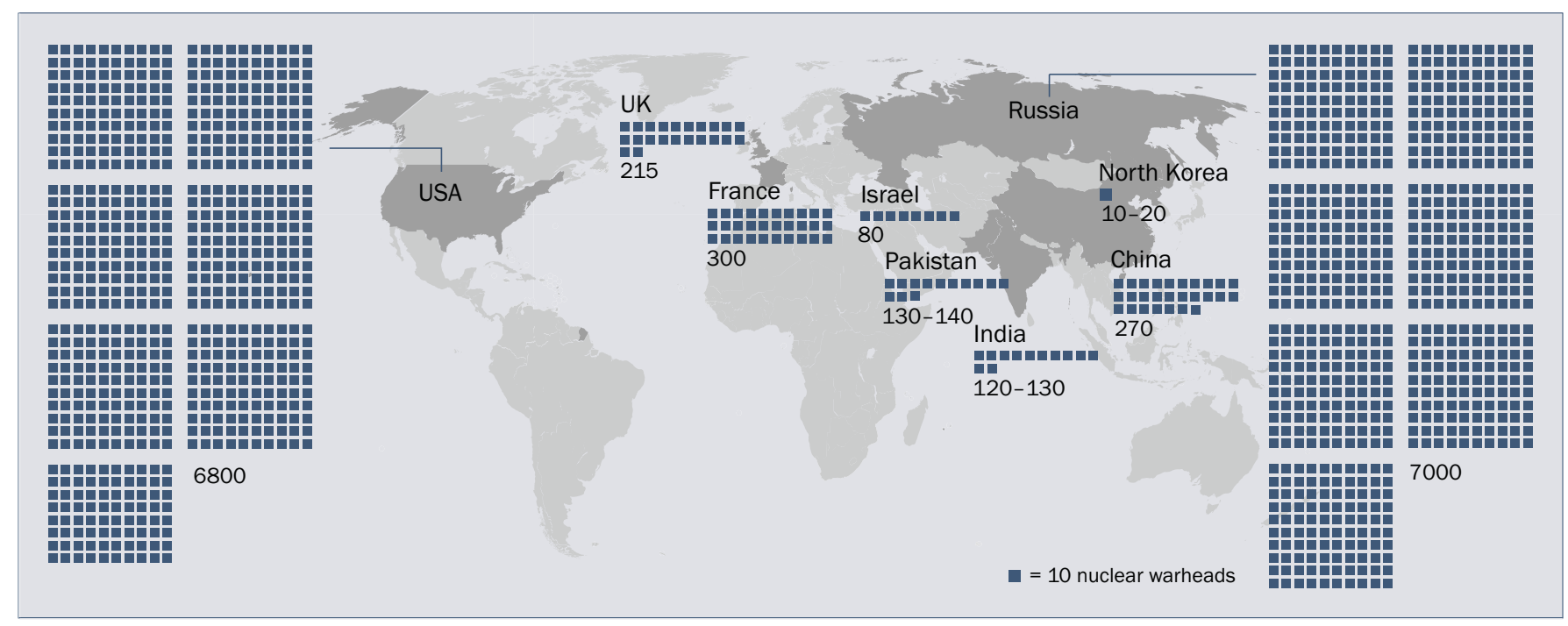

Figure 3. Total warhead holdings of all nuclear-weapon possessing states (the United States, Russia, the United Kingdom, France, China, India, Pakistan, Israel and North Korea), 2017

Note: All figures are approximate.

China has invested considerable resources in building the naval infrastructure needed to support the SSBN fleet.

\section{INDIAN NUCLEAR FORCES}

At the beginning of 2017 India was estimated to have an arsenal of up to 130 nuclear weapons. This represented an increase in the size of the Indian nuclear stockpile from the 110-120 warheads estimated in the SIPRI nuclear data for 2016. India's nuclear doctrine is based on the principle of a minimum credible deterrent and no-first-use of nuclear weapons, but there has been no official statement specifying the required size of the arsenal.

India is gradually expanding the size of its nuclear weapon stockpile as well as its infrastructure for producing nuclear warheads. It plans to build six fast breeder reactors, which will significantly increase its capacity to produce plutonium for weapons. India is also currently expanding its uranium enrichment capabilities with the construction of a new unsafeguarded gas centrifuge facility. India's expanded centrifuge enrichment capacity has been motivated by plans to build new naval propulsion reactors, but the potential excess capacity could also signify its intent to move towards thermonuclear weapons by blending the current plutonium arsenal with uranium secondaries.

India continues to prioritize work on the Agni family of land-based nuclear-capable ballistic missiles. It is currently conducting flight tests of a new road-mobile, canister-launched ballistic missile, the Agni-V, which reportedly will have a near-intercontinental range and be capable of reaching targets throughout China. The missile is expected to be inducted into service in 2017.

India continues to develop the naval component of its triad of nuclear forces in pursuit of an assured second-strike capability. The Indian Navy inducted its first indigenously built nuclear-powered submarine, INS Arihant, into service in 2016. It will carry a two-stage 700-kilometre range SLBM that is 
currently undergoing testing. India is developing a more advanced SLBM that will have a range of up to $3500 \mathrm{~km}$.

\section{PAKISTANI NUCLEAR FORCES}

As of January 2017 Pakistan was estimated to possess a stockpile of up to 140 warheads. This marked an increase from the 120-130 warheads estimated in the SIPRI nuclear data for 2016.

Pakistan is expanding its capabilities to produce fissile materials for nuclear weapons. Its current warhead designs are believed to use highly enriched uranium (HEU), which is produced at two centrifuge facilities. However, Pakistan has been expanding its main plutonium production complex at Khushab, Punjab, which consists of four operational heavy-water nuclear reactors and a heavy-water production plant, as well as constructing a new reprocessing plant at another site. Some non-governmental analysts have predicted that the size of Pakistan's nuclear stockpile will increase significantly over the next decade, although estimates of the increase in warhead numbers vary considerably depending on assumptions about Pakistan's production capabilities.

While aircraft constitute Pakistan's most mature nuclear delivery system, the government has prioritized the development of nuclear-capable landbased ballistic and cruise missiles. Pakistan currently deploys two types of road-mobile short-range ballistic missiles and has developed two types of medium-range ballistic missiles. One longer-range variant under development, the Shaheen-III missile, will be capable of reaching targets throughout India.

Pakistan has developed nuclear-capable short-range missiles that appear to be intended for tactical nuclear roles and missions. The development of so-called battlefield nuclear weapons reflects the pursuit of what Pakistan officials describe as a 'full-spectrum deterrence' posture. Their purpose is to offset India's superior conventional forces in limited conflict scenarios.

Pakistan has acknowledged that it is seeking to match India's nuclear triad by developing a sea-based nuclear force. There has been considerable speculation that the sea-based force will initially consist of nuclear-armed SLCMs deployed on submarines or on surface ships.

\section{ISRAELI NUCLEAR FORCES}

Israel continues to maintain its long-standing policy of nuclear opacity. It neither officially confirms nor denies that it possesses nuclear weapons. Israel is estimated to have approximately 80 nuclear weapons. Of these, around 30 are gravity bombs for delivery by aircraft. The remaining 50 weapons are for delivery by Jericho II medium-range ballistic missiles, which are believed to be located along with their mobile launchers in caves at a military base east of Jerusalem. The status of a new Jericho III intermediate-range ballistic missile is unknown.

There are unconfirmed reports that Israel may be equipping its fleet of six German-built Dolphin class diesel-electric submarines with nuclear-armed SLCMs. Israel has consistently denied these reports, and the reliability of many of them is uncertain. 
SIPRI is an independent international institute dedicated to research into conflict, armaments, arms control and disarmament. Established in 1966, SIPRI provides data, analysis and recommendations, based on open sources, to policymakers, researchers, media and the interested public.

\section{GOVERNING BOARD}

Ambassador Jan Eliasson, Chair (Sweden)

Dr Dewi Fortuna Anwar (Indonesia)

Dr Vladimir Baranovsky (Russia)

Ambassador Lakhdar Brahimi (Algeria)

Espen Barth Eide (Norway)

Ambassador Wolfgang

Ischinger (Germany)

Dr Radha Kumar (India)

The Director

\section{DIRECTOR}

Dan Smith (United Kingdom)

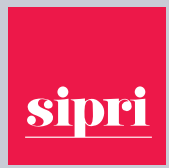

STOCKHOLM INTERNATIONAL PEACE RESEARCH INSTITUTE Signalistgatan 9 SE-169 72 Solna, Sweden Telephone: +4686559700 Email:sipri@sipri.org Internet: www.sipri.org

\section{NORTH KOREAN NUCLEAR FORCES}

In January and September 2016 North Korea carried out its fourth and fifth nuclear test explosions at the underground test site in the north-east of the country. It had previously conducted three nuclear tests at the site in 2006, 2009 and 2013. The estimated yields (explosive energy) of the tests have progressively increased.

It is estimated that North Korea may have built 10-20 nuclear warheads using plutonium separated from the spent fuel produced by the research reactor located at Yongbyon. North Korea is believed to be increasing its limited holdings of weapon-usable plutonium, although assessments differ about the scale and pace of the increase. In 2016 North Korea publicly acknowledged that it was producing HEU for nuclear weapons. However, little is known about North Korea's stock of HEU or its uranium enrichment capacity.

North Korea is expanding and modernizing its ballistic missile force, which consists of at least 10 types of indigenously produced short-, mediumand intermediate-range systems that are either deployed or under development. Among the systems being tested is a new solid-fuelled SLBM. In 2016 North Korea conducted missile tests at an unprecedented rate, carrying out 24 flight tests of different missile systems with mixed results.

North Korea is believed to have prioritized developing a long-range ballistic missile that can deliver a nuclear warhead to mainland USA. Based on photos taken at military parades in 2016 and 2017, analysts assess that North Korea may have two road-mobile ICBMs under development. A possible shorter-range variant of one of the missiles was successfully flight tested in May 2017. In addition, North Korea may have made some technical progress towards building an ICBM based on its three-stage Unha space launch vehicle that placed satellites in orbit in 2012 and 2016.

There is no publicly available evidence to confirm North Korea's claim following the September 2016 nuclear test that it has built a nuclear warhead that is sufficiently compact to be delivered by a ballistic missile. However, many analysts assess that North Korea is probably able to build a 'miniaturized' warhead that can be delivered by short- and medium-range missiles.

\section{ABOUT THE AUTHORS}

Shannon N. Kile (United States) is a Senior Researcher and the Head of the Nuclear Weapons Project in SIPRI's Disarmament, Arms Control and Non-proliferation Programme.

Hans M. Kristensen (Denmark) is the Director of the Nuclear Information Project at the Federation of American Scientists (FAS) and a SIPRI Associate Senior Fellow. 